\title{
Career Development in Schizophrenia: A Heuristic Framework
}

\author{
Deborah Gioia, Ph.D.
}

\begin{abstract}
Adults with schizophrenia continue to have poor rates of competitive employment. We have learned how to support individuals in the workplace with supported employment (SE); but have paid limited attention to early vocational identity development, work antecedents, illness characteristics, and career preferences. Vocational identity development is an important and natural condition of human growth for all persons and is well-researched in career counseling. For young adults with schizophrenia, the predictor of positive work outcome with the most evidence has been that working competitively prior to illness leads to better chances for work post-diagnosis. A heuristic framework is proposed to conceptualize how preillness vocational development (paid and unpaid) plus life cycle supports can provide direction to the individual in their work recovery.
\end{abstract}

KEY WORDS: Schizophrenia; vocational identity development; work recovery.

\section{INTRODUCTION}

Real world employment outcomes for individuals with severe mental illnesses, specifically, schizophrenia, have been described as being somewhere between meager and abysmal over the three decades that data have been collected and reported (Anthony \& Jansen, 1984; Bond \& McDonel, 1991; Cook, 2002; Lehman, 1995). While these outcomes can be improved with psychosocial interventions, the gains are modest

Address Correspondence to Deborah Gioia, Assistant Professor, University of Michigan School of Social Work, 1080

S. University Avenue, Rm 3702, Ann Arbor, MI 48109; e-mail: dgioia@umich.edu. 
and strategies for improving treatment effectiveness are needed (Bustillo, Lauriello, Horan, \& Keith, 2001). Despite attention to vocational rehabilitation supports to achieve work, there has been no satisfactory framework to assist in understanding why some persons with schizophrenia work competitively post-diagnosis, and why some don't return to paid work. Three general notions contribute to a partial understanding of work restoration in young adults: first, the presence of negative symptoms and cognitive impairments negatively affects competitive employment (Anthony, Rogers, Cohen, \& Davies, 1995; Lysaker \& Bell, 1995); second, possessing adequate social competence and a strong preference for paid work appear to predict motivation for job procurement and tenure at any age (Kee et al., 2003; Massel et al., 1990; Mueser et al., 2001); and third, status as a Social Security Disability Insurance (SSDI) recipient negatively affects competitive employment outcomes for those newly diagnosed (Ho, Andreasen, \& Flaum, 1997; MacDonald-Wilson, Rogers, \& Anthony, 2001). While it is important to pay attention to all contributions to work recovery, it is equally important to provide a systematized means to understand early work experiences, aspirations, career preferences and antecedents, and strategies that guide career development in the young adult prior to illness onset. The heuristic framework presented in this paper will utilize case examples to scaffold understanding of pre-illness career development in young adults with schizophrenia as a guide and preparation for work recovery post-diagnosis.

Understanding that there are many unique differences in vocational outcomes, this framework takes an individual life-span development approach, paying particular attention to how vocational growth changes over time and through illness phases. Three assumptions have shaped the development of this framework. First, no individual is devoid of vocational growth and development, despite the fact that young adults with schizophrenia are often treated as 'blank slates' vocationally by mental health professionals and persons in their social network. There are different routes to occupational growth and a breadth of antecedents in vocational development, but each of us has unique interests and desire to explore them (Schmitt-Rodermund \& Vondracek, 1999). Second, many individuals with schizophrenia are quite able to articulate the derailment they have experienced in vocational growth and a structured interview creates a means for describing their work and illness histories. Third, attention to career growth and maturity in the non-mentally ill is more dynamic and does take into account context 
and life-span development in a way that is not reflected in vocational rehabilitation for the seriously mentally ill (Schoon \& Parsons, 2002). Building on these three assumptions, the development of the heuristic framework in this paper will first include a literature review of the constructs and theories of vocational recovery, vocational identity, and career development. Second, two case studies will help illustrate the personal landscape of vocational recovery and demonstrate the importance of attending to vocational identity growth and development. Last, the paper will conclude with a discussion of how the framework may contribute to clinical applications, and to a better understanding of the importance of early vocational growth in young adults diagnosed with schizophrenia.

\section{VOCATIONAL RECOVERY}

The concept of work recovery is firmly established as one of the cornerstones of psychosocial rehabilitation for adults. Harding, Brooks, Ashikaga, Strauss, and Breier (1987), Anthony (1994), Spaniol (1994), and DeSisto, Harding, McCormick, Ashikaga, and Brooks (1995) have pioneered general concepts of illness recovery, such as hope, healing, empowerment, self-efficacy and growing beyond the catastrophic effects of the illness. Researchers learned about recovery from long-term studies and from the direct experiences of mental health consumers (Jacobson \& Greenley, 2001). Conceptual models of illness have been useful to providers over many years. For example, in schizophrenia, the vulnerability-stress-protective factors model (Nuechterlein \& Dawson 1984; Nuechterlein et al., 1992) has been an organizing tool to examine factors that impede or promote the course of the disorder. While not a recovery model, the vulnerability model has proved helpful in identifying preexisting conditions, current stresses, and the individual's environmental supports and strengths. These factors are equally important in recovery. While some tension exists in the field about what recovery means and whether full recovery is possible, at this point there is some mutual understanding of this optimistic term among consumers, mental health professionals and family members. According to The President's New Freedom Commission on Mental Health, 2003, "Recovery refers to the process in which people are able to live, work, learn and participate fully in their communities. For some individuals, recovery is the ability to live a fulfilling and productive life despite a disability. For others, recovery implies the reduction or 
complete remission of symptoms." As Mueser et al. (2002) state, "What is critical about illness recovery is the personal meaning that each individual attaches to the concept". So too with work recovery where the idea of attaching personal meaning to the concept of work is one that can be richly explored and used to guide rehabilitation.

One main premise of the framework presented here is that postillness work recovery is deeply entwined with the overall process of vocational/career development that begins early in life but is impacted by illness. Particular attention needs to be given to the vocational development that is a natural condition of human growth that all human beings engage in as they move from childhood to adulthood and try-out possible career choices. Children, as young as seven, have demonstrated their acquisition of vocational knowledge (Jordan \& Pope, 2001). Yet for those with schizophrenia it often seems that early vocational identity development is not emphasized after illness onset. In the manual for Individual Placement and Support (IPS; Becker \& Drake, 1993), acknowledgement is made that individuals may be "stuck in a kind of vocational adolescence" but advice is given to move the person into a phase of obtaining employment as an antidote to being stuck. In-depth interviews given to 20 young adults about their early vocational experiences contributed to vocational identity connection rather than vocational inertia (Gioia, 2000). Analyzing and reporting personal meanings ascribed to vocational recovery is a relatively new but essential area of investigation (Gioia, 2000; Provencher et al., 2002; Roe, 2001) and contributes to our overall understanding of work recovery. Most adults possess mental representations of what it means to work and persons with mental illness are no different; yet studies of patterns and meanings of employment recovery are sparse. A holistic, integrated synthesis of work and illness recovery is not yet available in the literature.

\section{VOCATIONAL IDENTITY}

The possession of a clear and stable picture of one's goals, interests, and talents is one definition of vocational identity (Holland, Daiger, \& Power, 1980; Swanson \& Gore, 2000). This construct has been found to correlate positively with nearly all desirable vocational outcomes and negatively with nearly all undesirable ones. Forming a vocational identity is one of the core interpersonal struggles of development described by Erikson (1960). Whether one achieves mastery of vocational 
identity depends in part on the outcome of finding personal meaning in vocational explorations. Finding meaning in work is lifelong but initial meaning may be complicated by the onset of schizophrenia. Vocational identity crises happen whether one has schizophrenia or not, but may become more profound with the added complication of illness.

The development of a vocational identity is captured in work choices, commitment, and experimentation. It is imbedded in narratives or subjective schemas that individuals form around seeing themselves as workers and describing this vision (Bujold, 2004). Attained milestones of vocational development need not be lost when a person becomes ill, but recognizing what has been preserved requires assistance. Subjectivity or person-focused studies have not been given the central position that other avenues of research have enjoyed (Strauss, 1992; Strauss \& Davidson, 1997). In order to understand the development of vocational identity and use it to enhance vocational recovery, we need to pay close attention to the individual's rich and subjective vocational history. Each individual is an expert on their own vocational trajectory, and this trajectory can be used to reflect and reinforce vocational identity. Far too few studies have connected functional outcomes, such as work, to subjective experience (Bradshaw \& Brekke, 1999; Brekke, Levin, Wolkon, Sobel, \& Slade, 1993; Roe, 2001). First person accounts of vocational development in persons with severe mental illness can contribute to the construction of a new way of thinking about vocational identity.

\section{THE ROLE OF CAREER DEVELOPMENT}

With very few exceptions (Fabian, 2000), we have abandoned thinking about competitive work for young adults with schizophrenia as part of a "normal" career development pattern. Baron \& Salzer (2000) described the discouragement felt by individuals in service-industry positions at or near minimum wage. Medical models of mental disorder may also delimit vocational growth as they tend to place emphasis on stress aversion as a way to protect against relapse and view work as a stress generator (Marrone, Gandolfo, Gold, \& Hoff, 1998; Rutman, 1994). Young adults are at a developmental stage where the desire for work and expression of long-term career goals is normal. It is also possible that prohibition of this expression may therefore produce a greater stress.

To date, the predictor of vocational success and the capacity to work has been repeatedly emphasized by the following notion: if individuals 
worked prior to becoming ill, they are much more likely to work after diagnosis (Anthony \& Jansen, 1984; Lehman \& Steinwachs, 1998; Mueser et al., 2001; Strauss \& Carpenter, 1972; Tsang, Lam, Ng, \& Leung, 2000). This empirically derived conclusion has been the underpinning of vocational rehabilitation thought and action, operating without sufficient challenge for years. Vocational specialists may use this assessment information about paid work to guide employment prospects for the consumer. Lehman and Steinwachs (1998) recommended in their patient outcomes study (PORT) that persons with schizophrenia should be offered vocational services if they have a history of prior competitive employment. These guidelines translated into some individuals with a work history being guided toward a return to competitive work while others without a history of paid employment were directed toward lower risk forms of activity (i.e. skills-training, 'in-house' employment). The emphasis on work prior to illness leading to work after illness as the best work outcome predictor has helped some individuals and hindered others. Thus, a central idea in this heuristic framework is that gains from individual vocational identity development, and not just paid employment, can be utilized to build a bridge to work re-establishment.

\section{ARE CAREER COUNSELING THEORIES RELEVANT IN SCHIZOPHRENIA?}

Career theories provide a framework for helping to understand how people form interests, make choices, and pursue occupational goals (Lent, Brown, \& Hackett, 2000). Although this concept has proved helpful in a normative understanding of career development, it has not been applied to vocational understanding of individuals with schizophrenia. Career counseling, derived from vocational development theory, is best described as an assistive discipline which can be enacted throughout the lifespan when individuals are first thinking about careers, have delayed careers due to a range of life events or change or retire from careers (Holland, 1973; Manuele, 1984). There is a long history of career research in developmental psychology. Donald Super (1963) developed a life-span model of 'normal' vocational self-concept from observations of male 9th graders in private schools. In this theoretical model, the individual moves in a stepwise manner through three exploratory sub-stages (tentative, transition and trial) before establishing a career choice and eventually career stabilization. In the 
evolution of his work, Super (1990) recognized that people differ in abilities, needs, values, interests, traits and self-concepts and thus, any individual may be well suited for not one, but a number of different occupations.

According to Super (1963), vocational choice has 5 component phases (crystallizing, specifying, implementing, stabilizing and consolidating) that occur as part of an overall exploratory stage in adolescence. It is within the exploratory vocational stages (ages 14-20) that the onset of schizophrenia may occur. Therefore, vocational growth may get tabled at a critical juncture of observing and "trying-on" possible work roles. The attention of the young adult may be diverted toward illness symptoms and away from vocational opportunity. Although Super (1990) never accounted for gender, illness, trauma, disability, racial or cultural diversity in his model, he made important contributions to understanding phases of career maturity and the negotiation of a vocational self-concept.

The work of Lent, Brown, and Hackett (1994) enriched Super's original theory. The Social Cognitive Career Theory (SCCT) has provided a broader context for examining career development, which incorporated age, race, and gender as well as environmental and personal factors that may influence vocational maturation. SCCT accounts for individual strengths and internal resources as well as external sources of support (e.g., financial, educational). In SCCT, social cognitive and social learning theories figure prominently (Bandura, 1986). Selfefficacy is the perception of one's ability to perform a given task or behavior. Self-efficacy may be a mediating variable in implementing vocational interests and may play a role in efforts expended to get and keep a job (Betz, 1999). Vocational self-efficacy is acquired in four key ways: (1) by prior vocational performance accomplishments; (2) by vicarious learning through modeling others' occupational behavior; (3) by encouraging verbal messages from significant others; and (4) by lowering anxiety in order to improve one's functioning in a supportive, low-stress environment. Self-efficacy varies with time, developmental age and vocational situation (Lent \& Brown, 1996). Vocational selfefficacy is initiated before one becomes ill and is affected by serious illness, but may be preserved through environmental supports.

To summarize, literature on vocational identity, development and recovery informs the core theoretical components of this heuristic framework. The field of vocational rehabilitation for persons with severe mental illness has been dominated by the notion that vocational 
success is only likely when one has pre-illness experience with paid work. To date, these vocational theories have not been applied to persons with severe mental illness. However, vocational development and identity theories strongly suggest that there is far more to vocational development than simply paid work experience (Lent \& Brown, 1996). It is postulated that young adults have clearly begun vocational identity formation before diagnosis (Schmitt-Rodermund \& Vondracek, 1999). Therefore, this heuristic framework will begin with integrating normative notions of vocational identity development with the themes which emerge from two case studies of young adults with schizophrenia (Gioia, 2000) to understand interacting patterns of work and illness which influence work recovery.

\section{PRODUCING INDIVIDUAL WORK/ILLNESS TRAJECTORIES}

\section{Model Explanation}

One way to think beyond the traditional framework used to guide vocational recovery is to produce a visual representation. The work/illness trajectory spans three phases of illness: premorbid, illness onset, and illness recovery on one side of the model; and provides work milestones on the other. In the diagram, the large arrow suggests that a greater emphasis is placed on early vocational development as it encompasses both the premorbid/prodromal illness phase. The third aspect of the model includes the individual's articulation of the internal and external resources that were important in the maintenance of vocational identity development. For example, noteworthy personal career role models would be placed under 'external' supports in the premorbid phase (e.g., an Uncle who paints), while pursuit of rock climbing or interest in meditation may represent an 'internal' strength and coping strategy in both pre-morbid and post-diagnosis phases (see figure 1).

To obtain the information for creation of the trajectory, Gioia (2000) developed global questions to help define phases of work and illness. Questions were asked in the broad categories of: (1) individual and familial notions of work ethic; (2) strengths gained from pre-illness paid or unpaid work; (3) personal understanding of stage of career development; (4) current desire and motivation to return to work; (5) potential impact of the illness on work from the individual's point of view; (6) proposed supports deemed necessary to maintain vocational growth;

(7) one's current view of work meaning; and (8) whether career-based 


\section{FIGURE 1}

\section{Individual Work \& Illness Trajectory}

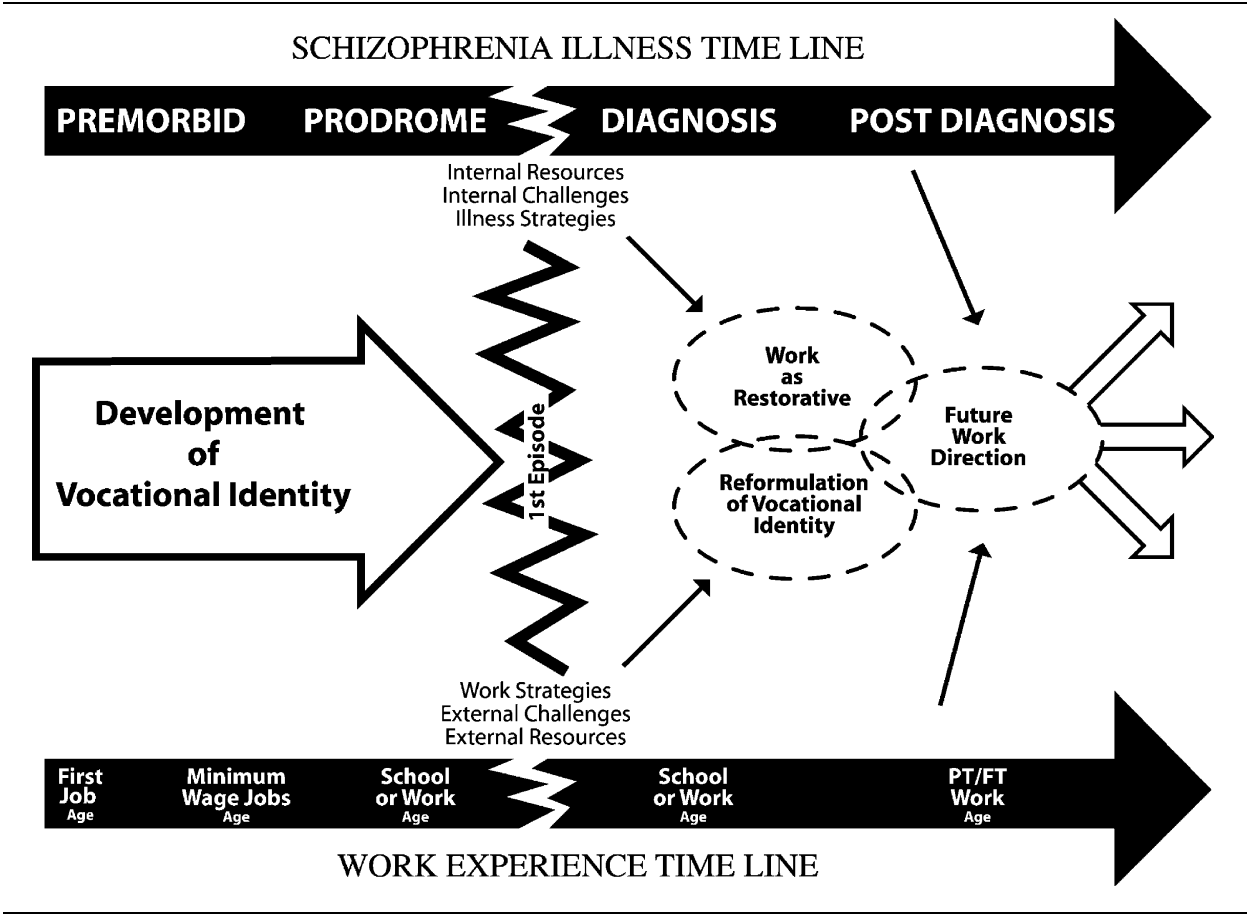

employment would provide more personal satisfaction and a desire to continue to work.

The 'thunderbolt' in the diagram represents illness onset and possible derailment of vocational development. Some individuals might be able to continue their jobs post-diagnosis, although this scenario is not common. Although the dividing line between health and illness may not be as severe as depicted in the diagram, many young adults describe work lives as strikingly different before and after diagnosis (Gioia, 2000). As health is restored, there can be an integration of illness experience with personal growth and vocational development. How well this is accomplished is unique to each person. Important external and internal supports are part of the trajectory for both symptom and work recovery. Arranging the supports in the diagram is helpful for seeing areas of separateness and overlap.

The amount of time for restoration of work function will be different for each person. In the post-diagnosis phase, the diagram provides an 
opportunity to separate vocational recovery into three phases, represented by the three ellipses: (1) the continuing illness experience; (2) the reformulation of vocational identity; and (3) future work restoration efforts. The experience of illness (as phases) may change how individuals think about themselves, their present, future, and past (Garro, 1994; Kleinman, 1988).

\section{WORK/ILLNESS TRAJECTORY—TWO CASE STUDY EXAMPLES}

Case study is a means to particularize rather than generalize. Case study has the power to highlight both the unique and ordinary features of individual experience (Stake, 1995). Heuristic models often develop from picking apart the themes of a case study and trying to understand the lessons imbedded within the themes. For this article, two cases were chosen because they represent similarities and differences in the road back to competitive employment post-diagnosis, and thus provide an important aid to learning about vocational recovery. The two individuals were part of a sample of 20 who were interviewed about the meaning of work in their lives since their diagnosis of schizophrenia (Gioia, 2000). The narratives of Mark and Keisha illuminate some core features of the proposed career development model where attention to early vocational identity development shapes the outcome of work post-diagnosis.

In order to collect a thorough history and to build the work/illness trajectory, two sessions of at least two hours duration are required. In addition, other sources of information (e.g., parents, counselors) can prove beneficial in corroborating the history. The question guiding the understanding of work identity formulation and recovery for these two persons was continually guided by a persistent curiosity about 'why' despite difficult psychotic episodes and persisting symptoms he/she was able to recover sufficiently to obtain competitive employment, and 'how' they went about it. The model for obtaining vocational history is a continuous development until an agreement has been reached about vocational milestones, internal and external resources between the interviewer, interviewee and significant others.

\section{MARK}

Mark (a chosen pseudonym) was selected because his vocational history was illustrative of three facets of the heuristic framework of career 
development: (1) rich early vocational identity development; (2) severe illness symptoms that interrupted work; and (3) continued progress toward work restoration and recovery. At the time of the interviews Mark was married and in his late 30s. I knew Mark and his family for over 10 years through his participation in an NIMH longitudinal study. I recognized that Mark had a strong work ethic but it wasn't until he agreed to be interviewed that I gained a deeper appreciation for the contributions of his early vocational identity development. Mark was selected for the interview because he was able to articulate his work history and the challenges and supports that helped him maintain work over time.

Mark brought considerable vocational identity development to his first episode of schizophrenia. He is one of those rare individuals who nurtured a career dream from childhood and never lost sight of this vision. As a child he would watch construction site activity for hours, and as a teenager he experimented with his dream by working with a relative for the summer on a construction project. His parents concurred with this description of his vocational formation. It was always important to him. However, Mark's path to work was not easy. He developed auditory hallucinations and paranoid delusions in the latter part of his teen years just at the point where paid work was a possibility. His story provided many examples of how working got him through difficult symptom exacerbations even before his diagnosis was defined. Mark recounted, "I would just pound nails until I couldn't hear the voices anymore, and I would go home exhausted and sleep." Work provided concrete examples of personal triumph and self-efficacy"When I got my contractor's license, I knew I could do anything". Work enhanced Mark's self-esteem immeasurably as a contributing member of society. When he was too symptomatic to work for a construction company, he was able to do helpful things for his family and friends (e.g., painting, mending fences), which reinforced the notion of giving back to those who had helped him. Mark repeatedly described work as therapy and a positive challenge in the interview.

Analysis of Mark's narrative produced the development of the first illness and work trajectory. The trajectory was tailored by inserting key personal milestones in illness and vocational development as well as barriers, resources, strategies and support. For example, Mark had good role models for work in both his parents (pharmacist, mental health administrator) and an uncle (a psychiatrist). Mark graduated high school, came from an intact family, had reliable work skills and a lifelong expressed interest in work-all positive predictor variable and 
evidence of the development of an early work identity according to career theorists (Super, 1963). Barriers described were persistent financial struggles, inability to achieve full independence, child support for a child fathered in his $20 \mathrm{~s}$, and medication side effects. If we continue to list internal sources of support for work post-diagnosis they would include: (1) a sustained internal belief in conquering the positive symptoms of schizophrenia; (2) no evidence of ongoing negative symptoms; (3) normal range of self-esteem and quality of life scores as measured by standardized tests; and (4) expressed belief in preservation of work skills, despite symptoms. His external sources of support after his first episode were: (1) family involvement; (2) family generated work opportunities; (3) lasting friendships and ability to form relationships; (4) trade school competency; (5) continued role as a parent; and (6) ongoing use of mental health supports. Although Mark never used a formal supported employment model, support from family members was very meaningful. It was not just their expressed belief in his ability to return to work but their actual role in finding him jobs within the family and community that "reminded" Mark that his preillness work roles were still viable.

It is worth mentioning one post-diagnosis challenge that overlapped both work and illness histories. Mark developed a long-term medication side effect of tardive dyskinesia, in the form of pronounced eye blinking and squinting, which caused him to 'stand out' at work. He decided to wear sunglasses indoors to cope and explain his 'problem' as light sensitivity. Eventually he strategized with his psychiatrist to obtain Botox injections that slightly paralyzed the eye muscles, treated the spasmodic blink response, and enabled him to take off his sunglasses and remove a social workplace barrier.

There is no doubt that Mark lives in a continual stage of vocational growth. Work has provided structure, social rituals, and 'normal' status. He plans to have his own construction company one day and future work directions, as illustrated by the multiple arrows in the diagram, are varied. Instead of a 'capped' vocational trajectory, Mark connected with his pre-illness vocational growth, restored his vocational functioning post-illness, received encouragement from his social network and is living a life filled with opportunity, hope and a good functional status. $\mathrm{He}$ has a future probably marked by transition to vocational consolidation and finally to career advancement. Mark's persistent view of 'work as restorative' informed the development of the initial work/illness trajectory and served as the first heuristic. Mark was in agreement that the map represented key aspects of his vocational development. 


\section{KEISHA}

A second case study offers both challenge and support for the heuristic framework. Keisha is a single African-American female in her late 30s with a 10-year-old son who is in foster care. The interviews took place at the apartment Keisha shared with her mother in a low-income neighborhood under the flight path to LA International Airport. It was often hard to hear her answers to questions even though I was less than two feet away. Keisha has the same level of positive symptoms as Mark (i.e. daily hallucinations), however in addition she had much higher negative symptoms such as affective flattening, alogia, avolitionapathy, anhedonia, and attention (Schedule for the Assessment of Negative Symptoms, SANS; Andreasen, 1983). She also has discomforting side-effects from the medication. Keisha has a delusional belief that she is possessed by several spirits and this belief interferes with her ability to socialize and ultimately with her return to work.

Keisha revealed a lot about her vocational identity development in her in-depth interviews. Keisha's mother had been sewing to support her family_ "off and on for as long as I can remember". Since the family struggled so much for basic subsistence, Keisha was encouraged by her mother to get a job before she graduated high school. She started out as a tray aide in a convalescent center when she was 17 and was promoted to cook's helper. Keisha got along with her supervisor, acquired a variety of cooking skills, and was able to contribute to the family. All of these activities raised her self-esteem, sense of self-efficacy, social skills, and overall value both at home and at work. The vocational identity path gets complicated when Keisha becomes pregnant. It seems from her narrative that she may also be having some symptoms at this point but she did not receive any treatment. Her work history becomes fragmented. Her desire to work is strong but she loses jobs due to interpersonal and poor judgment problems. When she couldn't find steady work in the community she assisted her mother in a home health situation where her mother had been employed for 15 years. When her son was born she collected welfare benefits and stopped work for over 4 years. It was during this time that symptoms of schizophrenia were at their peak.

Keisha's first hospitalization resulted in her son being put into foster care with a relative. Her son's father died shortly after the birth from long-term effects of substances. Keisha has never had full custody or responsibility for her son but sees him everyday. Although Keisha's schizophrenia has never remitted she has never stopped believing that 
she would be well enough to return to work. She returned to work at a small convalescent hospital until the voices got so bad that she had to leave. It took another four years and about ten hospitalizations before she would return to work again. She stated, "I wanted to be able to get back into the working force. I wanted to be back around my friends and be back around people that was alright". She did go back to work but was still symptomatic. When I asked why now? She said, "I feel like the voices are never going to go away... and I have to take care of myself. I needed clothes, I needed personal hygiene stuff... and my money wasn't stretching to buy these things".

Keisha was not as successful in her work recovery as Mark. Her long delay in returning to work and her persistent symptoms made her job tenure "five paychecks" long. Keisha had less evident support than Mark and more environmental barriers, but it was clear from her narrative that she possessed an equally strong early vocational identity development as Mark, especially in her discussion of her mother as a role model. Keisha did not graduate high school; she had no reliable transportation; and was limited to very low wage positions in her community. However, she reframed these positions as positive and career-enhancing. She liked working as a cook and felt she was good at it. Keisha was the product of an environment where it was acceptable to receive benefits and she was ill enough to continue on disability, yet her desire to resume work could not be ignored. The 'case' of Keisha contributes to the formulation of the heuristic, her outcome speaks to the need for earlier support and intervention in work recovery.

\section{IMPLICATIONS OF THE FRAMEWORK}

Newly diagnosed young adults are at particular risk for becoming vocationally derailed by their illness and many will not accomplish the work recovery that Mark and Keisha have achieved, as low reported occupational outcomes of first episode studies demonstrate (Tohen et al., 2000). Barriers to seamless vocational recovery are many: (1) an early dependence on government disability assistance often encouraged by family and mental health workers (Ho et al., 1997); (2) limited availability and quality of vocational services for those with mental illness (Noble, Honberg, Hall, \& Flynn, 1997; Twamley, Jeste, \& Lehman, 2003); (3) a steadfast belief by some mental health practitioners and family members that competitive employment may create undue stress and inhibit full symptom recovery (Marrone et al., 1998); (4) limited 
availability of jobs due to economic conditions; and (5) stigma (Corrigan, 1998).

It is clear that a new view of career development needs to be put forth. The heuristic framework proposed in this paper draws attention to several key areas that have largely been ignored: First, we should not dismiss the importance of vocational growth achieved prior to illness. Very little research attention has focused on the phases of employment, including pre-morbid work (Bond, Drake, Mueser, \& Becker, 1997). Second, we need to understand core notions of career development theory and seek to blend these notions into psychosocial rehabilitation practices. Third, many young adults with schizophrenia, despite cognitive, negative, and positive symptoms, desire an opportunity to work (Becker et al., 1996). Acknowledging their vocational interests soon after illness onset provides an avenue for recovery that has been neglected.

There are many individuals with schizophrenia who have been assisted in work recovery by empirically supported models like supported employment, Individual Placement and Support (IPS) and Assertive Community Treatment (ACT). Supported employment has been consistently more effective than prevocational training (Bond et al., 1997; Crowther, Marshall, Bond, \& Huxley, 2001; Drake et al., 1999; Twamley et al., 2003); however, success rates have been modest at best and strategies for improving the effectiveness of these interventions are needed (Bustillo et al., 2001). The framework presented here is not meant as a replacement for these effective interventions, rather this attention to vocational identity development is viewed as providing augmentation to the goals of supported employment, respect for consumer preference, the overall goal of getting persons back to work without lengthy delays, and to improving the effectiveness of current best practices models. There are individuals for whom supported employment has not been a panacea, and these individuals may be helped by additional attention to vocational identity development as well as creating a bridge to post-diagnosis career development.

Clinical applications are possible. The work/illness template in this heuristic model can be developed as an intervention tool for vocational specialists and as a means to expand boundaries around how we view young adults and their return to work. In career counseling it is routine to 'teach the test', meaning that immediate feedback is given from career information collected from the individual. The act of paying close attention to early work experience may keep individuals and their families as invested in a vocational future as they were before the individual became ill. We need to communicate that 
vocational growth is important, continuous, and not lost when illness occurs. Vocational aspirations can be met with support and guidance. Clinicians could produce their own vocational trajectory as an example of the nonlinearity of vocational development. Additionally clinical application may be in the area of workplace accommodations, since many persons are not well educated about workplace protections and how to enact important workplace resources and supports (Gioia \& Brekke, 2003).

Qualitative methods have not been widely used in understanding complex functional outcomes, like work, and we have little subjective information about work restoration. This concept did not arise from speculation about work recovery or observation of specific vocational programs in action; rather the development of the framework arose from three areas: (1) years of clinical work with young adults with schizophrenia; (2) the integration of vocational development theories; and (3) the particular findings from case studies of young adults. Mark and Keisha's evidence of strong early work identity was a key factor in future work restoration. Attention to vocational identity development can be a preventive notion for individuals with schizophrenia. Positive case exemplars are extremely important for vocational rehabilitation and we have few current examples in the literature.

It is only through the continued pursuit of subjective experience in the area of work recovery that we can acquire the knowledge necessary to change enduring patterns of low employment and non-career work trajectories. A vision for the future lies in understanding what strategy of understanding career development and choice might work best for which individual (Lent, 2001). The usefulness of a heuristic framework lies in thoroughly understanding how vocational identity development interacts with individual characteristics, features of the illness, resources, supports, and barriers. Important next steps could involve a series of pilot studies with young adults with schizophrenia seeking supported employment services in order to see if attention to vocational identity in the form of an interview prior to start of services can improve the outcomes from vocational services and provide a bridge to work recovery and ultimately a satisfying and meaningful vocational future. Finally, much needs to be understood about work and the sociocultural compatibility of the framework. Recent studies have explored cultural relativity of career development in various ethnic and racial groups, but further exploration is needed (Hardin, Leong, \& Osipow, 2001; West, 1988). 


\section{ACKNOWLEDGMENTS}

This work was supported in part by NIMH Grant R03 MH60481-01, "Meaning of work for young adults with schizophrenia: a mixed method study". The author would like to thank Dr. Keith Neuchterlein and the UCLA Aftercare Program participants and Dr. John Brekke, University of Southern California, School of Social Work.

\section{REFERENCES}

Andreasen, N. C. (1983). Scale for the assessment of negative symptoms, Iowa City: University of Iowa.

Anthony, W. A. (1994). The vocational rehabilitation of people with severe mental illness: Issues, myths. Innovations and Research, 3(2), 17-23.

Anthony, W. A., \& Jansen, M. A. (1984). Predicting the vocational capacity of the chronically mentally ill. American Psychologist, 39, 537-544.

Anthony, W. A., Rogers, S. E., Cohen, M., \& Davies, R. R. (1995). Relationship between psychiatric symptomatology, work skills, and future vocational performance. Psychiatric Services, 46(4), 353-358.

Bandura, A. (1986). Social foundations of thought and action: A social cognitive theory, Englewood Cliffs, NJ: Prentice Hall.

Baron, R. C., \& Salzer, M. S. (2000). The career patterns of persons with serious mental illness: Generating a new vision of lifetime careers for those in recovery. Psychiatric Rehabilitation Skills, 4(1), 136-156.

Becker, D. R., \& Drake, R. E. (1993). A working life: The Individual Placement and Support (IPS) Program, Concord, NH: New Hampshire-Dartmouth Psychiatric Research Center.

Becker, D. R., Drake, R. E., Farabaugh, A., \& Bond, G. R. (1996). Job preferences of clients with severe psychiatric disorders participating in supported employment programs. Psychiatric Services, 47(11), 1223-1226.

Beng-Choon, Ho., Andreasen, N., \& Flaum, M. (1997). Dependence on public financial support early in the course of schizophrenia. Psychiatric Services, 48(7), 948-950.

Betz, N. E. (1999). Getting clients to act on their interests: Self-efficacy as a mediator of the implementation of vocational interests. In M. L. Savickas, \& A. R. Spokane (Eds.), Vocational interests: Meaning, measurement, and counseling use, Davies-Black Publishing, Palo Alto, CA.

Bond, G. R, Drake, R. E., Mueser, K. T., \& Becker, D. R. (1997). An update on supported employment for people with severe mental illness. Psychiatric Services, 48(3), 335-346.

Bond, G. R., \& McDonel, E. C. (1991). Vocational rehabilitation outcomes for persons with psychiatric disabilities: An update. Journal of Vocational Rehabilitation, 1(3), 9-20.

Bradshaw, W., \& Brekke, J. S. (1999). Subjective experience in schizophrenia: Factors influencing self esteem, satisfaction with life and subjective distress. American Journal of Orthopsychiatry, 69(2), 254-260.

Brekke, J. S., Levin, S., Wolkon, G. H., Sobel, E., \& Slade, E. (1993). Psychosocial functioning and subjective experience in schizophrenia. Schizophrenia Bulletin, 19(3), 599-608.

Bujold, C. (2004). Constructing career through narrative. Journal of Vocational Behavior, 64(3), $470-484$.

Bustillo, J. R., Lauriello, M. D., Horan, W. P., \& Keith, S. J. (2001). The psychosocial treatment of schizophrenia: An update. American Journal of Psychiatry, 158, 163-175.

Cook, J. A. (2002). The promise of vocational rehabilitation: Results from the SAMSHA Employment Intervention Demonstration Project (EIDP). [Report] University of Chicago, Department of Psychiatry. http://www.psych.uic.edu/eidp.

Corrigan, P. W. (1998). The impact of stigma on severe mental illness. Cognitive and Behavioral Practice, 5(2), 201-222. 
Crowther, R. E., Marshall, M., Bond, G. R., \& Huxley, P. (2001). Helping people with severe mental illness obtain work: A systematic review. British Medical Journal, 322, 204-208.

DeSisto, M. J., Harding, C., McCormick, R. V., Ashikaga, T., \& Brooks, G. W. (1995). The Maine and Vermont three-decade studies of serious mental illness: I. Matched comparison of crosssectional outcome. British Journal of Psychiatry, 167(3), 331-338.

Drake, R. E., \& McHugo, G. J., et al. (1999). A randomized trial of supported employment for inner-city patients with severe mental disorders. Archives of General Psychiatry, 56, 627-633.

Erikson, E. H. (1960). Childhood and society, New York: W.W. Norton \& Co., Inc.

Fabian, E. S. (2000). Social cognitive theory of careers and individuals with serious mental health disorders: Implications for psychiatric rehabilitation programs. Psychiatric Rehabilitation Journal, 23(3), 262-269.

Garro, L. C. (1994). Narrative representations of chronic illness experience: Cultural models of illness, mind, and body in stories concerning the temporomandibular joint (TMJ). Social Science Medicine, 38(6), 775-788.

Gioia, D., \& Brekke, J. S. (2003). Knowledge and use of employment provisions of the Americans with Disabilities Act (ADA) by young adults with schizophrenia. Psychiatric Services, 54(3), 302-304.

Gioia, D. (2000). The meaning of work for young adults with schizophrenia: A mixed method study. Doctoral dissertation. California: University of Southern. Dissertation Abstracts International, 63/02, p. 755, August 2002..

Hardin, E. E., Leong, F. T., \& Osipow, S. H. (2001). Cultural relativity in the conceptualization of career maturity. Journal of Vocational Behavior, 58(1), 36-52.

Harding, C. M., Brooks, G. W., Ashikaga, T., Strauss, J. S., \& Breier, A. (1987). The Vermont longitudinal study of persons with severe mental illness, II: Long-term outcome of subjects who retrospectively met DSM-III criteria for schizophrenia. American Journal of Psychiatry, 144(6), 727-735.

Holland, J. L. (1973). Making vocational choices: A theory of careers, Englewood Cliffs, NJ: Prentice-Hall.

Holland, J. L., Daiger, D. C., \& Power, P. G. (1980). Some diagnostic scales for research in decision-making and personality: Identity, information and barriers. Journal of Personality and Social Psychology, 39, 1191-1200.

Jacobson, N., \& Greenley, D. (2001). What is recovery? A concept model and explication. Psychiatric Services, 52, 482-485.

Jordan, T. E., \& Pope, M. L. (2001). Developmental antecedents to adolescents' occupational knowledge: A 17-year prospective study. Journal of Vocational Behavior, 58, 279-292.

Kee, K. S., Green, M. F., Mintz, J., \& Brekke, J. S. (2003). Is emotion processing a predictor of functional outcome in schizophrenia?. Schizophrenia Bulletin, 29(3), 487-497.

Kleinman, A. (1988). The illness narratives: Suffering, healing \& the human condition, New York: Basic Books.

Lehman, A. F., \& Steinwachs, D. M. (1998). Patterns of usual care for schizophrenia: Initial results from the Schizophrenia Treatment Outcomes Research Team (PORT) Client Survey. Schizophrenia Bulletin, 24(1), 11-20.

Lehman, A. (1995). Vocational rehabilitation in schizophrenia. Schizophrenia Bulletin, 21, 645656.

Lent, R. W. (2001). Vocational psychology and career counseling: Inventing the future. Journal of Vocational Behavior, 59, 213-225.

Lent, R. W., \& Brown, S. D. (1996). Social cognitive approach to career development: An overview. The Career Development Quarterly, 44, 310-321.

Lent, R. W., Brown, S. D., \& Hackett, G. (1994). Toward a unifying social cognitive theory of career and academic interest, choice and performance. Journal of Vocational Behavior, 45, 79-122.

Lent, R. W., Brown, S. D., \& Hackett, G. (2000). Contextual supports and barriers to career choice: A social cognitive analysis. Journal of Counseling Psychology, 47(1), 36-49.

Lysaker, P., \& Bell, M. (1995). Negative symptoms and vocational impairment in schizophrenia: Repeated measurements of work performance over six months. Acta Psychiatrica Scandinavica, 91, 205-208.

MacDonald-Wilson, K., Rogers, E. S., \& Anthony, W. A. (2001). Unique issues in assessing work function among individuals with psychiatric disabilities. Journal of Occupational Rehabilitation, 11(3), 217-232. 
Manuele, C. (1984). Modifying vocational maturity in adults with delayed career development. Vocational Guidance Quarterly, 33, 101-112.

Marrone, J., Gandolfo, C., Gold, M., \& Hoff, D. (1998). Just doing it: Helping people with mental illness get good jobs. Journal of Applied Rehabilitation Counseling, 29(1), 37-48.

Massel, H. K., Liberman, R. P., Mintz, J., Jacobs, H. E., Rush, T. V., Giannini, C. A., \& Zarate, R. (1990). Evaluating the capacity to work of the mentally ill. Psychiatry, 53, 31-41.

Mueser, K. T, Corrigan, P. W., Hilton, D. W., Tanzman, B., Schaub, A., Gingerich, S., Essock, S. M., Tarrier, N., Morey, B., Vogel-Scibilia, S., \& Herz, M. I. (2002). Illness management \& recovery: A review of the research. Psychiatric Services, 53(10), 1272-1284.

Mueser, K. T., Salyers, M. P., \& Mueser, P. R. (2001). A prospective analysis of work in schizophrenia. Schizophrenia Bulletin, 27(2), 281-296.

Noble, J. H., Honberg, R. S., Hall, L. L., \& Flynn, L. M. (1997). A legacy of failure: The inability of the federal-state vocational rehabilitation system to serve people with severe mental illness, Alexandria, VA: A report of the National Alliance for the Mentally Ill (NAMI).

Nuechterlein, K. H., \& Dawson, M. E. (1984). A heuristic vulnerability/stress model of schizophrenia. Schizophrenia Bulletin, 10(2), 300-309.

Nuechterlein, K. H., Dawson, M. E., Gitlin, M., Ventura, J., Goldstein, M., Snyder, K.S., Yee, C., \& Mintz, J. (1992). Developmental processes in schizophrenic disorders: The UCLA longitudinal studies of recent-onset schizophrenia. Schizophrenia Bulletin, 18, 387-425.

President's New Freedom Commission on Mental Health. (2003). www.mentalhealthcommission.gov/.

Provencher, H. L., \& Gregg, R., et al. (2002). The role of work in the recovery of persons with psychiatric disabilities. Psychiatric Rehabilitation Journal, 26(2), 132-144.

Roe, D. (2001). Progressing from patienthood to personhood across multidimensional outcomes in schizophrenia and related disorders. Journal of Nervous and Mental Disease, 189(10), 691-699.

Rutman, I. D. (1994). How psychiatric disability expresses itself as a barrier to employment. Psychosocial Rehabilitation Journal, 17(3), 15-35.

Schmitt-Rodermund, E., \& Vondracek, F. W. (1999). Breadth of interests, exploration, and identity development in adolescence. Journal of Vocational Behavior, 55, 298-317.

Schoon, I., \& Parsons, S. (2002). Teenage aspirations for future careers and occupational outcomes. Journal of Vocational Behavior, 66, 262-288.

Spaniol, L. (1994). The recovery workbook: Practical coping and empowerment strategies for people with psychiatric disability, Boston, MA: Center for Psychiatric Rehabilitation.

Stake, R. E. (1995). The art of case study research, Thousand Oaks, CA: Sage Publications.

Strauss, J. S. (1992). Subjectivity. The Journal of Nervous and Mental Diseases, 184(4), $205-212$.

Strauss, J. S., \& Carpenter, W. T. (1972). The prediction of outcome in schizophrenia: I. Characteristics of outcome. Archives of General Psychiatry, 27, 739-746.

Strauss, J. S., \& Davidson, L. (1997). Mental disorders, work, and choice. In R. J. Bonnie, \& J. Monahan (Eds.), Mental disorder, work disability, and the law, University of Chicago Press, Chicago.

Super, D. E. (1963). Vocational development in adolescence and early adulthood: Tasks and behaviors. Career development: Self-concept theory, NewYork: College Entrance Examination Board.

Super, D. (1990). A life-span, life-space approach to career development. In D. Brown, \& L. Brooks (Eds.), Career choice and development: Applying contemporary theories to practice, 2nd edition, Jossey-Bass Inc, San Francisco, CA.

Swanson, J. L., \& Gore, P. A. (2000). Advances in vocational psychology theory and research. In S. D. Brown, \& R. W. Lent (Eds.), Handbook of counseling psychology, 3rd edition, John Wiley \& Sons, New York.

Tohen, M., Strakowski, S. M., Zarate, C., Jr., Henner, J., Stoll, A. L., Suppes, T., Faedda, G. L., Cohen, B. M., Gebre-Medhin, P., \& Baldessarini, R. J. (2000). The McLean-Harvard firstepisode project: 6-Month symptomatic and functional outcome in affective and nonaffective psychosis. Biological Psychiatry, 48, 467-476.

Tsang, H., Lam, P., Ng, B., \& Leung, O. (2000). Predictors of employment outcome for people with psychiatric disabilities: A review of the literature since the mid' 80s. Journal of Rehabilitation, 66(2), 19-31.

Twamley, E., Jeste, D., \& Lehman, A. (2003). Vocational rehabilitation in schizophrenia and other psychotic disorders: A literature review and meta-analysis of randomized controlled trials. The Journal of Nervous and Mental Disease, 191(8), 515-523.

West, D. K. (1988). Comparisons of career maturity and its relationship with academic performance. Journal of American Indian Education, 27(3), 1-7. 